\title{
An Exploratory Study Of Intrinsic \& Extrinsic Motivators And Student Performance In An Auditing Course
}

Songtao Mo, Purdue University Calumet, USA

\begin{abstract}
The objective of this study is to investigate the association of intrinsic and extrinsic motivators and student performance. This study performs an exploratory analysis and presents evidence to demonstrate that intrinsic motivators affect the connection between external motivators and student performance. The empirical tests follow the framework developed by Baron and Kenny (1986) and examine the mediation effect on the data collected from an undergraduate auditing course. The results indicate that there exists a partial mediation effect of voluntary online quizzes (a measure of intrinsic motivator) on the association between mandatory in-class quizzes (a measure of external motivator) and course performance. The findings offer basis for interesting implications, suggesting that mandatory external motivators (e.g., in-class quizzes) are of less value with the presence of other viable motivational techniques (e.g., online quizzes). Voluntary online quizzes help foster learner intrinsic motivation and hence bear more importance with student performance. Educators may consider using techniques that can boost intrinsic motivation in teaching practices.
\end{abstract}

Keywords: Intrinsic Motivator; Extrinsic Motivator; Student Performance; Mediation Effect

\section{INTRODUCTION AND MOTIVATION}

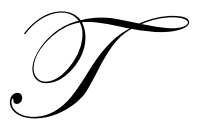

he initial motivation of this study was derived from the instructor's reflection on student comments regarding quizzes. The instructor who received the comments used both online quizzes and in-class quizzes in an undergraduate auditing course. The requirements for the two types of quizzes are different. The online quizzes were strictly voluntary and the students could practice with the online quizzes with no constraints throughout the semester. On the other hand, the in-class quizzes were closed-book and administered by the instructor in a class session. The instructor collected and graded the in-class quizzes based on accuracy of student responses. Moreover, the points earned from most in-class quizzes were counted towards the course grade. On the end-of-semester evaluations, some students anonymously commented on the two types of quizzes. While the students acknowledged the usefulness of online quizzes, they suggested including online quizzes in the evaluation matrix of the course.

The instructor's assessment of student comments reveals that, despite the exclusion in the course evaluation matrix, voluntary online quizzes are more important to student performance. Unlike with in-class quizzes, student motivation to actively engage in the online quizzes does not have direct bearing on the items in the course evaluation system. The coexistence of online and in-class quizzes in one course provided a setting to empirically investigate the underlying motivators for the two types of quizzes. As such, the examination of the relationship between voluntary online quizzes and mandatory in-class quizzes, and the association of these two types of motivational techniques and student performance, would provide insights on enhancements to effectively engage students in the learning process.

Voluntary student participation in the online quizzes constitutes a natural experiment by occurrence. Therefore, the adoption of proxies for intrinsic and external motivators is facilitated by the respective voluntary and mandatory characteristics of online quizzes and in-class quizzes. The objective of this study is to investigate the role 
of extrinsic and intrinsic motivators, proxied by mandatory in-class and voluntary online quizzes, in the student learning process. Intuitively speaking, the use of quizzes has a positive association with student performance. This study further explores the individual and interactive effect of voluntary and mandatory quizzes, and investigates the role of voluntary quizzes in the relationship between mandatory quizzes and course performance. The research advances prior studies and sheds light on teaching practices in regards to how to effectively motivate students in the learning process.

The reminder of the paper is organized as follows: Literature review is presented in section 2 to develop a proposition for empirical tests; the course structure and the background for data collection is discussed in section 3; the research method and empirical results are discussed in section 4; lastly, followed by the discussion of implications and summary is presented in section 5 .

\section{LITERATURE REVIEW}

A rising number of college students are losing sight of their own responsibility as part of the learning process. Most instructors are having the experience that the students come to classes merely for the points of attendance or mandatory in-class quizzes. These students tend to be easily distracted from classroom discussions and engage in their own activities (e.g., texting to friends). These passive learners are more likely to miss the important components of learning and subsequently lose interest in the course.

In light of the above phenomena, educators recognize the importance of effectively motivating the students and raising self-awareness of student responsibility in learning. The topic of motivating students to engage in class activities has been extensively explored by previous literature. One of the popularly used methods is in-class quizzes. In-class quizzes are used to check student attendance, with the primary intent of boosting student preparation. (e.g., Bacdayan 2004). Research has also shown that the usefulness of mandated quizzes in different formats, as a means of external motivator, is more useful when supplemented by techniques that foster intrinsic motivation (Bacdayan 2004). Examination of the relationship between external and intrinsic motivators has been limited to self-reported data in behavioral science. Empirical tests with objective measurements are hindered by the availability of qualified data.

In-class quizzes are considered to be an effective and efficient instructional technique to promote student learning. Instructors also use this method to track the students' progress and provide feedback for further improvements. From a learner's perspective, the student gains the opportunity of continuous assessment of their learning progress. With the wide spread use of computers and access to internet, computerized and online quizzes have been used as a motivational method to supplement in-class lectures. Unlike in-class quizzes, online quizzes offer students flexible studying schedules and the opportunities to obtain immediate feedback (Harter and Harter 2004).

While prior studies agree on the usefulness of quizzes on the enhancement of student attitudes towards the subject, the evidence is inconclusive regarding the effectiveness of quizzes on student performance (Farrelly and Hudson 1985; Vruwink and Otto 1987; Harter and Harter 2004; Azorlosa and Renner 2006). Vruwink and Otto (1987) adapt the expectancy theory and find no evidence to support that students taught with motivational teaching techniques achieved higher scores on exams. Harter and Harter (2004) find that the use of online quizzes in an introductory economics course is not associated with improved student performance. Azorlosa and Renner (2006) find that, despite better preparation and enhanced studying reported by the students, quizzes have no impact on student performance on exams. Meanwhile, Norman (1981) suggests that pedagogical techniques with a feedback system are related to enhanced learning outcomes. Elikai and Baker (1988) also provide empirical evidence that quizzes with rewards can be used to improve student performance. Johnson et al (2002) document that student effort, measured by student activities on repeated computerized quizzes, lead to better student performance.

The contradictory results of previous research suggest that the mechanism of quizzes as a motivational method operates in a more complex way than how it appears. Bacdayan (2004) surveys management faculty members on the role of mandatory quizzes and calls for more in-depth analyses of the effectiveness of quizzes and other alternative teaching techniques in motivating students. The results of the survey suggest that mandatory 
quizzes are appropriate but in some circumstances may not be necessary in boosting student preparation (Bacdayan 2004). The diminished importance of mandatory quizzes can be explained by the study by Deci (1971), which proposes that intrinsic motivators, relative to the extrinsic motivators, are more effective in engaging the students in the learning process.

Based on data obtained from the natural experiment, this paper attempts to explore the mechanism of motivational techniques in the format of quizzes. Specifically, this study examines the effect of the extrinsic motivator (proxied by mandatory in-class quizzes) on student performance, with the presence of intrinsic motivator (proxied by voluntary online quizzes). Previous research implies that the intrinsic motivator has an effect on the relationship between the extrinsic motivation and the student performance (e.g., Deci 1971; Bacdayan 2004). Intuitively speaking, external motivators that are associated with enhanced studying would have positive effect on course performance. However, external motivators alone are not the influential factor in determining performance. The external motivators are effective on the performance when coupled with intrinsic motivations. The above description fits the profile of mediation effect and I develop the following proposition:

Proposition 1: Voluntary online quizzes have a mediation effect on the relationship between mandatory in-class quizzes and student performance.

\title{
BACKGROUND
}

The dataset for this study was collected from an auditing course from a Midwest regional campus of a public university. The majority of the student body is composed of non-traditional students, who work full time and attend college part time. Auditing is a required course for students majoring in the Bachelor of Science in accounting and an elective for students majoring in Bachelor of Science in management with a concentration in accounting. The entering student is required to earn a minimum grade of $\mathrm{C}$ in Intermediate Accounting II. Students with outstanding performances in Intermediate Accounting I may enroll in the course with the permission of the instructor.

This Auditing course is the first auditing course offered in the undergraduate program and aims at giving the student an understanding of the philosophy and environment of the auditing profession. The course highlights the nature and economic purpose of the auditing profession, auditing standards, professional conduct, legal liability, audit evidence, audit planning, internal control, and audit working papers. The lectures cover 9 chapters from the textbook by Whittington and Pany (2008). The description of the chapters covered in the course is detailed in Table 1.

Table 1: Description of Chapters covered in the Auditing Course

\author{
Whittington, O. R. \& K. Pany (2008). Principles of Auditing \& Other Assurance Services (17 ${ }^{\text {th }}$ Edition). New York, \\ NY: McGraw-Hill Irwin. \\ Chapter 1: The Role of the Public Accountant in the American Economy \\ Chapter 2: Professional Standards \\ Chapter 3: Professional Ethics \\ Chapter 4: Legal Liability of CPAs \\ Chapter 5: Audit Evidence and Documentation \\ Chapter 6: Audit Planning, Understanding the Client, Assessing Risks, and Responding \\ Chapter 7: Internal Control \\ Chapter 17: Auditors' Reports \\ Chapter 18: Integrated Audits of Public Companies
}

The dataset contains the observations of students enrolled in the auditing course in Fall 2009 and Spring 2010. A total of three sections of students is included in the sample, including two sections from Fall 2009 and one section from Spring 2010. The same instructor taught all three sections. The same course material was used and the exams had similar difficulty levels. 
The instructor prepared online quizzes for each chapter, which consist of various numbers of objective questions. The online quizzes were set to allow unlimited attempts and unlimited time for each attempt. The correct answers to the questions are available for student review after each attempt. The student use of the online quizzes was not mandatory and was strictly voluntary. In addition, the student grades from the voluntary online quizzes were not counted toward the course grade. As a follow-up measure, the instructor prepared in-class quizzes, which incorporated some of the identical objective questions from self-assessment quizzes and one essay question from lectures. In Fall 2009, twelve quizzes were given throughout the semester, including one quiz for each of the nine chapters, two evaluation quizzes, and one take home quiz. The four lowest grades were dropped at the end of the semester. In Spring 2010, the take home quiz was removed and the remaining eleven quizzes were given to the students, the three lowest grades were dropped when computing course grades. In both semesters, eight quizzes account for a total of $20 \%$ of the course grade. Further, three exams and two case studies accounted for a total of $60 \%$ and $20 \%$ of course grades, respectively. The first exam, which was $15 \%$ of the course grade, tests the student knowledge of chapters 1 to 4 . The second exam testing the chapters 5 to 7 comprised of $20 \%$ of the course grade. The final exam was a comprehensive exam and accounted for $25 \%$ of the course grade. The descriptive statistics are illustrated in Table 2.

Table 2: Descriptive Statistics

\begin{tabular}{|l|c|c|c|c|c|}
\hline \multicolumn{1}{|c|}{ Variable } & N & Minimum & Maximum & Mean & Std. Deviation \\
\hline Grade & 71 & 71 & 98 & 86.01 & 6.136 \\
\hline total self quiz & 71 & 1 & 260 & 202.86 & 67.576 \\
\hline Adj in class quiz & 71 & 140 & 200 & 188.73 & 12.445 \\
\hline
\end{tabular}

Grade: student course grade from the auditing course, in the format of percentage.

Total self quiz: the total of the highest grades from all self quizzes, 260 points maximum.

Adj in class quiz: the total of the grades from in-class quizzes (excluding quizzes in the format of feedbacks) counted towards final grades, 200 points maximum.

\section{RESEARCH METHOD AND EMPIRICAL RESULTS}

As discussed in previous section, the scores of most in-class quizzes are counted towards the course grade while the scores of the online quizzes were entirely irrelevant. As a result of the evaluation structure, the students tended to focus on their performance on the in-class quizzes based on their belief that the in-class quizzes were more directly related to course grades. On the other hand, most students were not aware of the importance of online quizzes (intrinsic motivators). Most students practiced the voluntary online quizzes (intrinsic motivators) with the intention to do well in the in-class quizzes (extrinsic motivators).

The nature of this exploratory study determines that the reliance on the existing theoretical framework on motivation and student performance is rather limited. Therefore, the model specification process utilizes both guidance from prior literature and the instructor teaching experience. The underlying reason to use external motivators (in-class quizzes) as the starting point is derived from the understanding of motivational techniques. It is apparent that the students are more likely to pay attention to those items included in the evaluation matrix. Some students stop with the extrinsic motivators (in-class quizzes), and others proceed to make the best use of the intrinsic motivators (online quizzes). Those who are highly motivated intrinsically tend to have higher course grades.

To account for the variables on different scales, I first standardize the variables and transform them into zscores. The z-score of a variable has mean of 0 and standard deviation of 1 . I follow the four steps described by Baron and Kenny (1986) to test the mediation effect of online quizzes.

Table 3 demonstrates the 4 paths required by Baron and Kenny to determine the mediation effect. Four regression tests are used to determine the mediation. The four regression equations are listed as followed:

Step 1: Test path C, which is the correlation between the predictor (in-class quizzes) and the outcome (course grade). This test attempts to establish a significant association between the predictor (in-class quizzes) and the outcome (course grades) that may be mediated. 
Step 2: Test path A, which is the correlation between the predictor (in-class quizzes) and the mediator (online quizzes). This test should establish that the predictor (in-class quizzes) should be positively related with the mediator (online quizzes).

Step 3: Test path B, which is the correlation between the mediator (online quizzes) and the outcome (course grade). This test should provide evidence that the mediator (online quizzes) and the outcome (course grade) are significantly connected.

Step 4: Test path C', which is the correlation between the predictor (in-class quizzes) and the outcome (course grade) with the presence of the mediator (online quizzes). In this step, the relationship between predictor (in-class quizzes) and outcome (course grade) should become insignificant after controlling the mediating effect of online quizzes. Meanwhile, the decrease in coefficient of the predictor (in-class quizzes), when compared with the coefficient of the model without the mediator, is also indicative of the mediation effect.

Table 3: Mediation Effect Paths

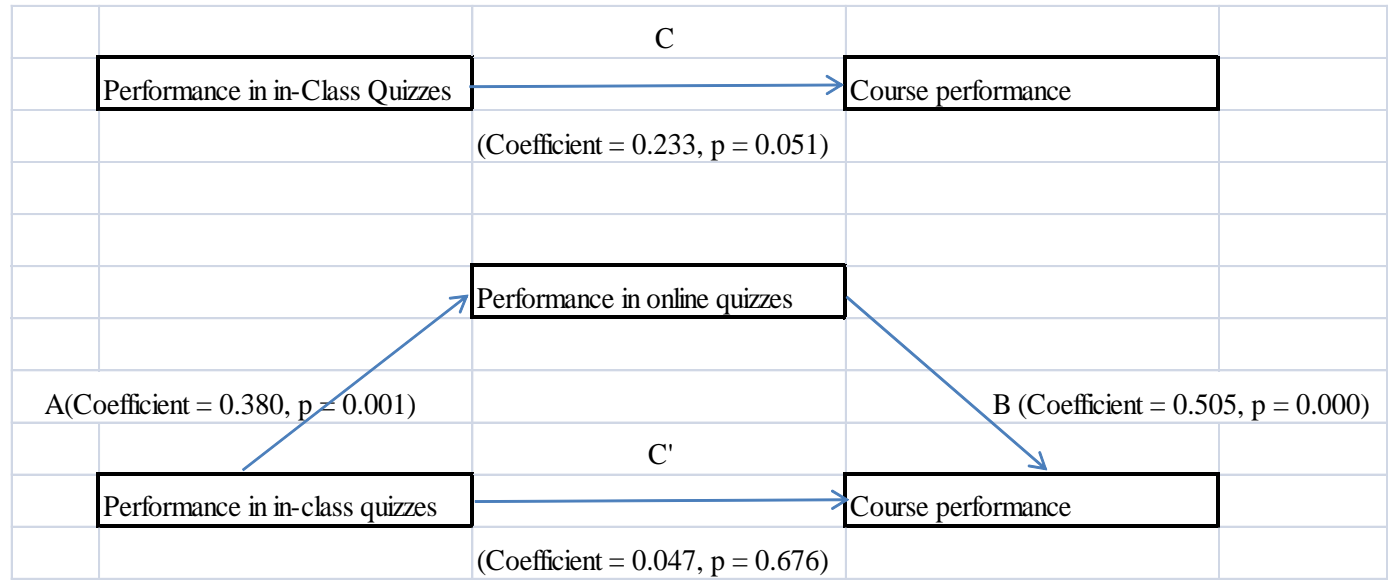

Table 4: Regression Models of Mediation Effects

\begin{tabular}{|l|l|l|c|c|c|}
\hline & \multicolumn{1}{|c|}{ outcome } & \multicolumn{1}{c|}{ predictor } & R Square & $\begin{array}{c}\text { coefficient } \\
\text { (predictor) }\end{array}$ & $\begin{array}{c}\text { p-value } \\
\text { (predictor) }\end{array}$ \\
\hline $\begin{array}{l}\text { Model 1 } \\
\text { Path C }\end{array}$ & Grade & In-class Quizzes & 0.054 & 0.233 & $0.051^{*}$ \\
\hline $\begin{array}{l}\text { Model 2 } \\
\text { Path A }\end{array}$ & Online Quizzes & In-class Quizzes & 0.145 & 0.380 & $0.001^{* *}$ \\
\hline $\begin{array}{l}\text { Model 3 } \\
\text { Path B }\end{array}$ & Grade & Online Quizzes & 0.255 & 0.505 & $0.000^{* *}$ \\
\hline $\begin{array}{l}\text { Model 4 } \\
\text { Path C' }\end{array}$ & Grade & $\begin{array}{l}\text { In-class Quizzes } \\
\text { Online Quizzes }\end{array}$ & 0.257 & 0.047 & 0.676 \\
\hline
\end{tabular}

$\mathrm{Z}$ scores are used in these regression models

**significant at $<0.05 ;$ *significant at $\mathrm{p}<0.10$

The empirical results of the four regression models, as illustrated in Table 4, corroborate the proposition that voluntary online quizzes have a mediation effect on the relationship between course performance and mandatory in-class quizzes. The coefficient of performance in in-class quizzes in the model of path C' was 0.047, decreased by $80 \%$ from the coefficient of path $\mathrm{C}$ (coefficient $=0.233$ ). In the meanwhile, the performance in in-class quizzes became insignificantly associated with course performance ( $\mathrm{p}$-value $=0.676$ ) with the presence of the mediator (performance in in-class quizzes). 
Sensitivity tests are performed by using various measures of online quizzes and in-class quizzes. A set of sensitivity tests with intrinsic motivators (online quizzes) and use extrinsic motivators (in-class quizzes) as the mediator indicate that extrinsic motivators barely mediate anything from the association between course performance and intrinsic motivators. The results empirically reinforce the conclusion that intrinsic motivators are much more important. Additionally, models with other control variables (e.g., Grade Point Average) also suggest that the results of the study are robust to model specifications and variable selection. In conclusion, the above results (untabulated) suggest that the partial mediation effect of intrinsic motivators (online quizzes) is robust.

\section{DISCUSSION AND SUMMARY}

The generalization of the empirical results of this study should be interpreted with caution in light of a specific course in one university. The findings may vary in teaching courses in other disciplines or in other learning environments. In spite of the limitations in the dataset, the study provides a basis for useful implications.

The findings suggest that mandatory in-class quizzes are, to some extent, an effective motivational technique. Contrary to most students' belief, the usefulness of mandatory in-class quizzes decreases dramatically with the presence of voluntary online quizzes. It is implied that voluntary online quizzes play a vital role in determining the student performance. The empirical evidence corroborates the significance of enhancing students' intrinsic motivation, as discussed in previous studies (Bacdayan 2004; Nolen 1988). Moreover, the positive coefficient (0.380) of path A, indicates a positive association between intrinsic motivator (voluntary online quizzes) and external motivator (mandatory in-class quizzes). The findings are consistent with previous research on the positive impact of external motivators on intrinsic motivators, proposing that students may gradually develop lifelong routines through external guidance and assistance. Instructors' use of mandatory in-class quizzes would motivate the students to spend time on the course material and may consequently kindle student interest in the field.

Despite disagreement over the format, the significance of motivational techniques can never be diminished. What seems explicit from this study is that the usefulness of some external motivators (e.g., mandatory in-class quizzes) has been exaggerated in practice. Having the students come to class is not the equivalent of fully engaging the students. The use of external motivator, which can easily accomplish the former, would hardly achieve the goal of the latter motivating the students in the learning process. Intrinsic motivators, which have a mediation effect on the relationship between external motivators and student performance, divert the contributed impact from external motivators. While external motivators may serve as a necessary technique to assist the students to start the development of healthy studying habits, internal motivators are nevertheless the more influential element leading to student success in the long run. Instructors may consider utilizing intrinsic motivators to supplement the external motivators to further boost student interest in the courses.

The priority implied in this exploratory study is a better understanding of the significance of intrinsic motivators. The analysis of intrinsic motivators sheds light on the nature of motivational techniques, and the challenges that the instructors face to engage the students. Further explorations on innovative motivational techniques carry rich potential to advance both educational research and teaching practice. The discussion of such motivational techniques could encourage educators to develop teaching methods that would foster student motivation and engagement, leading to improved student learning experience and enhanced quality of higher education.

\section{AUTHOR INFORMATION}

Songtao Mo, Ph.D. is an Assistant Professor of Accounting in the School of Management at Purdue University Calumet. Her research focuses on financial reporting, intangibles, and auditing. Her teaching interests include auditing and financial accounting. She received her Ph.D. in Management with specialization in Accounting from Case Western Reserve University in 2009. Dr. Mo holds the professional designation of Certified Fraud Examiner. 


\section{REFERENCES}

1. Azorlosa, J. L. \& C. H. Renner (2006). The Effect of Announced Quizzes on Exam Performance. Journal of Instructional Psychology 33(4), 278 - 283.

2. Bacdaya, P. (2004). Comparison of Management Faculty Perspectives on Quizzing and Its Alternatives on Quizzing and Its Alternatives. Journal of Education for Business, September / October, 5-9.

3. Baldwin, B. A. (1980) On Positioning the Quiz: An Empirical Analysis. The Accounting Review, LV (4), 664-671.

4. Baron, R. M. \& D. A. Kenny (1986). The Moderator-Mediator Variable Distinction in Social Psychological Research: Conceptual, Strategic, and Statistical Considerations. Journal of Personality and Social Psychology, 51 (6), 1173- 1182.

5. Battista, M. S. (1978). The Effect of Instructional Technology and Learner Characteristics on Cognitive Achievement in College Accounting. The Accounting Review, LIII (2), 477-485.

6. Bennett. J. A. (2000). Mediator and Moderator Variables in Nursing Research: Conceptual and Statistical Differences. Research in Nursing \& Health, 23, 415-420.

7. Deci, E. L. (1971). Effects of Externally Mediated Rewards on Intrinsic Motivation. Journal of Personality and Social Psychology, 18, 105-115.

8. Elikai, F. \& J. Baker. (1988). Empirical Evidence on the Effectiveness of Quizzes as a Motivational Technique. Issues in Accounting Education, 3 (2), 248-254.

9. Farrelly, G.E. \& E. J. Hudson (1985). How to Teach Introductory Accounting: Student View. Journal of Accounting Education, Spring, 47-56.

10. Francis, V. E. \& N. Schreiber (2008). What, No Quiz Today? An Innovative Framework for Increasing Student Preparation and Participation. Decision Sciences Journal of Innovative Education, 6 (1), 179-186.

11. Grove, W. A. \& T. Wasserman (2006). Incentives and Student Learning: A Natural Experiment with Economics Problem Sets. American Economic Review 96 (2), 447-452.

12. Hadsell, L. (2009). The Effect of Quiz Timing on Exam Performance. Journal of Education for Business, January / February, 135-140.

13. Harter, C. L. \& J. F. R. Harter (2004). Teaching with Technology: Does access to Computer Technology increase student achievement? Eastern Economic Journal 30, 507-514.

14. Moore, S., C. Armstrong \& J. Pearson (2008). Lecture Absenteeism in Higher Education: a Valuation Route to Understanding Student Motivation. Journal of Higher Education Policy and Management, 30 (1), $15-24$.

15. Shoulders, C. D. \& S. A. Hicks (2008). ADEPT Learning Cycles Enhance Intermediate Accounting Student Learning Success. Issues in Accounting Education 23 (2), 161-182.

16. Vruwink, D. R. \& J. R. Otto (1987). Evaluation of Teaching Techniques for Introductory Accounting Courses. The Accounting Review, LXII (2), 402-408. 


\section{NOTES}

